\title{
Formation of the structure and properties of composite materials based on copper powder during its reactionary mechanical alloying with titanium, carbon and oxygen
}

\author{
Valentin Smirnov ${ }^{1, *}$, Evgeny Shalunov ${ }^{1}$, Aleksandr Yanyushkin ${ }^{1}$, and Pavel Danilov ${ }^{1}$ \\ ${ }^{1}$ Chuvash State University, Joint R\&D Laboratories of Mechanically Alloyed Nano-Composite \\ Materials, their Technology and Quality, 428015 Cheboksary, Moscovsky Prospekt 15, Russia
}

\begin{abstract}
The results of studying the structure and properties of dispersion-strengthened composite materials of the $\mathrm{Cu}-\mathrm{Ti}-\mathrm{C}-\mathrm{O}$ system obtained by reactionary grinding of copper powder with additions of titanium powder ( $0 \ldots 5 \mathrm{wt} \%)$ and carbon in the form of graphite $(0 \ldots 1 \mathrm{wt} \%)$ in a high-energy ball mill of the attritor type in the presence of air. The regularities of the influence of titanium and graphite content on the hardness and electrical conductivity of the materials under study have been studied. It is shown that with an increase in the titanium content, the hardness increases and the electrical conductivity decreases. The hardness and electrical conductivity of materials under study dependences on the graphite content have the form of curves with maxima, which are observed at different values of the carbon content depending on the titanium content. By the method of X-ray phase analysis of the anode deposit of materials under study, it was found that the main strengthening phases are dispersion particles of titanium carbide. The composite materials under study of the $\mathrm{Cu}-\mathrm{Ti}-\mathrm{C}-\mathrm{O}$ system, due to the combination of high electrical conductivity, hardness and recrystallization temperature, can be an alternative for replacing beryllium bronze in many fields.
\end{abstract}

\section{Introduction}

As materials for the manufacture of electrodes for electrical resistance welding of corrosion-resistant steels and heat-resistant alloys, as well as reinforcing nets and lattices of reinforced concrete products, in general, dispersion-hardened nickel-beryllium bronzes CuBe2NiTi are used [1,2]. They have high values of hardness (up to $240 \mathrm{HB}$ ) and hightemperature strength with sufficiently good electrical conductivity (up to $45 \%$ of the electrical conductivity of copper). These bronzes are also used as a tool electrode for electrical discharge machining of metallic materials [3]. The high toxicity [4,5] of beryllium provides for the introduction of restrictions in many countries, including Russia, on the use of beryllium bronzes, which are not recommended for use in newly developed or upgraded equipment.

* Corresponding author: vms53@inbox.ru 
An alternative to beryllium-containing bronze can be heat-treatable alloys of the $\mathrm{Cu}-\mathrm{Ti}$ system with a titanium content of $1 . . .5 \mathrm{wt} \% \mathrm{Ti}$ [6-8]. An effective increase in the strength and electrical conductivity of $\mathrm{Cu}-\mathrm{Ti}$ alloys is observed as a result of quench hardening in water from $800 \ldots 950^{\circ} \mathrm{C}$ for $1 \ldots 10 \mathrm{~h}$ and subsequent aging at $450{ }^{\circ} \mathrm{C}$ for $1 \mathrm{~h}$ or more due to the precipitation of dispersed particles of the strengthening phase $\mathrm{Cu}_{4} \mathrm{Ti}$ or $\mathrm{Cu}_{3} \mathrm{Ti}$ [6-9]. The processes of supersaturated solid solution decomposition depending on temperature and time have been studied quite deeply in a number of works [6-10]. However, with an increase in the aging temperature above $500{ }^{\circ} \mathrm{C}, \mathrm{Cu}-\mathrm{Ti}$ alloys rapidly soften due to the processes of coagulation of dispersion particles of the strengthening phase $\mathrm{Cu}_{4} \mathrm{Ti}[9,10]$.

Unlike to the precipatation hardening $\mathrm{Cu}-\mathrm{Ti}$ alloys, dispersion-strengthened composite materials of the $\mathrm{Cu}-\mathrm{Ti}-\mathrm{C}$ system, obtained by mechanical alloying of copper with titanium and carbon in high-energy ball mills of planetary type [11-13], have a high strength and high electrical conductivity due to the formation of evenly distributed nanosized particles of titanium carbide and obtaining a lower concentration of dissolved titanium in the copper matrix. However, obtaining composite materials based on copper, dispersion-strengthened with titanium carbide TiC nanoparticles by mechanical milling of copper powder with additions of titanium and graphite powder or titanium bronze powder with the addition of graphite powder in planetary ball mills in argon or vacuum [11-13] - a rather lengthy, expensive and low-productivity process, which limits their widespread industrial application. A less costly and more productive method of obtaining dispersion-strengthened composite materials based on copper with a combination of high strength, electrical conductivity and softening temperature is the method of reaction milling of powdered copper with additions of alloying metal powder and graphite in high-energy ball mills - in attritors, without the use of a protective medium [ 14-17].Usually, metal powders capable of forming stable oxides or carbides with a high melting temperature in a copper matrix are used as alloying additives to obtain dispersion-strengthening phases [14 -17].

Due to their high stability in a copper matrix, a high level of physical and mechanical properties of such dispersion-strengthened composite materials is preserved during their operation at high temperatures, for example, as electrodes for resistance welding [15], as well as tool electrodes for electrical discharge machining. Electrodes made of these materials during butt welding tests of corrosion-resistant steels and heat-resistant alloys in production, as well as reinforcing nets and lattices of reinforced concrete products, showed a significant resource [18]. However, their further widespread introduction is limited by insufficient data on the relationship between the chemical composition of the charge and the structure and properties of materials specified, which does not allow optimizing these parameters and, thereby, even more increasing the resource of the welding tool and tool electrodes for electrical discharge machining from them.

Therefore, the main aim of this work is to study the effect of titanium and carbon content in an initial powder mixture on the formation of properties, structure, and phase composition of dispersion-strengthened composite materials of the $\mathrm{Cu}-\mathrm{Ti}-\mathrm{C}-\mathrm{O}$ system.

\section{Materials and study method}

The studies were carried out on materials made from mixtures of standard powders of copper PMS-1, titanium PTM-A, and graphite GK-3, which were preliminarily processed in a high-energy attritor in air. The compositions of powder mixtures under study varied in the content of titanium $(1,2,3$, and $5 \mathrm{wt} \%)$ and graphite $(0,0.25,0.45$, and $1.0 \mathrm{wt} \%)$.

The resulting granules were subjected to cold compaction into briquettes, which were then heated to $750^{\circ} \mathrm{C}$ and from these temperatures were extruded into rods $\varnothing$ of $13 \mathrm{~mm}$.

The microstructure was studied using the Zeiss Axio Vert A1 Mat metallographic microscope on sections obtained from materials after etching with a $10 \%$ ammonia 
solution. The structure was studied using the Next from NT-MDT atomic force microscope (AFM) on the surface of sections prepared by electropolishing in an electrolyte of the following composition: $1150 \mathrm{~g} / \mathrm{l}$ of $\mathrm{H}_{3} \mathrm{PO}_{4}, 95 \mathrm{ml} / \mathrm{l}$ of butyl alcohol and $\mathrm{H}_{2} \mathrm{O}$.

The phase composition of strengthening particles (dispersoids) in the material matrix was determined by electrolytic separation and subsequent X-ray phase analysis of the anode deposit using the DRON-3M X-ray diffractometer. An aqueous solution containing $3 \mathrm{wt} \%$ of $\mathrm{CuSO}_{4}, 3 \mathrm{wt} \%$ of $\mathrm{H}_{3} \mathrm{PO}_{4}$ and $3 \mathrm{wt} \%$ of ammonium citrate was used as the electrolyte.

The lattice period of the copper matrix was determined based on the center of gravity of a diffraction line from the (422) plane using an X-ray tube with a copper anode $\left(\lambda_{\text {Kaav. }}=0.154178 \mathrm{~nm}\right)$.

\section{Results and discussion}

\subsection{Hardness}

The dependence of the hardness of materials under study on the content of titanium and carbon in the form of graphite in the initial powder mixture (charge) is shown in Fig. 1.

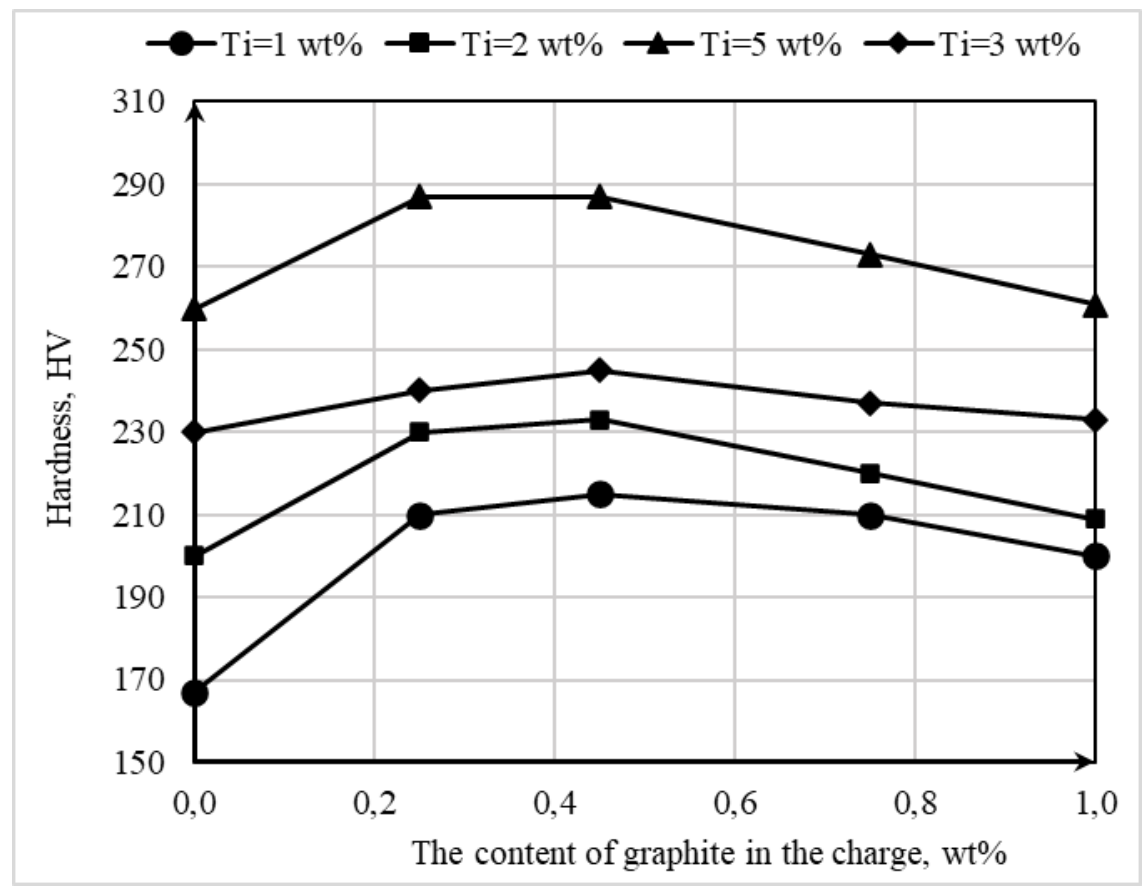

Fig. 1. The dependence of the hardness HV of composite materials under study on the titanium and graphite content in the charge.

An increase in the titanium content with the same amount of graphite in the composition of the charge leads to a significant increase in the hardness of materials under study. The maximum values of the hardness of materials under study at a fixed value of titanium are observed with a content of graphite within the range from $0.25 \mathrm{wt} \%$ to $0.5 \mathrm{wt} \%$. A further increase in graphite leads to a decrease in hardness.

Possible mechanisms of hardening of materials under study as a result of severe plastic deformation and solid-phase reactions occurring during high-energy processing of the initial powder mixture in an attritor with air access can be: 
- formation of a solid solution of $\mathrm{Cu}(\mathrm{Ti})$ due to the dissolution of titanium in copper;

- formation of dispersion particles of titanium carbide, copper and titanium oxides, as well as due to precipitation of the second phase of $\mathrm{Cu}_{4} \mathrm{Ti}$ during a supersaturated solution of $\mathrm{Cu}(\mathrm{Ti})$ decomposition;

- increase in the density of dislocations and grain refinement.

Naturally, in the process of intensive grinding in the attritor of a powder mixture based on copper with additions of titanium and graphite powders in the presence of air, the formation of copper and titanium oxides can occur. Additions of carbon in the form of graphite to the charge of materials under study provide the formation of stable dispersion phases in the form of titanium carbide TiC [14] and, as is known [16,17], promote the reduction of copper oxides. Such processes can occur both during processing of a powder mixture in the attritor and during hot extrusion of a briquette from granules at $750{ }^{\circ} \mathrm{C}$. The formation of dispersion phases of titanium carbide requires a mass ratio between carbon and titanium in the charge equal to 1:4. Then, to provide the reduction of copper oxides, it is necessary to have a higher content of graphite or titanium in relation to their equiatomic content. An excess of titanium atoms can also ensure the reduction of copper from oxides and the formation of titanium oxides.

\subsection{Electrical conductivity}

The results of measuring the electrical conductivity in relative units (\% IASC) of alloys under study depending on the titanium and graphite content in the charge are shown in Fig. 2.

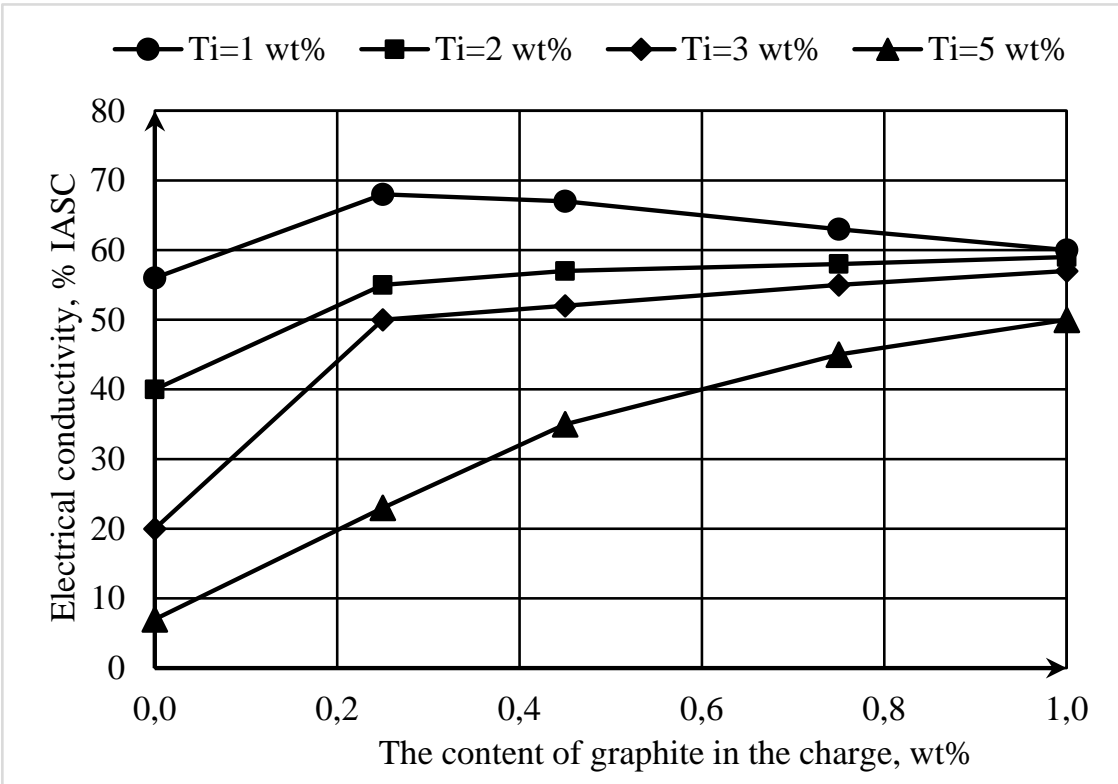

Fig. 2. The electrical conductivity of composite materials under study dependence on the titanium and graphite content in the charge.

As is known, the content of alloying elements and impurities in the crystal lattice of copper in the form of a solid solution strongly influences on the electrical conductivity of copper. An increase in the titanium content at an equal concentration of graphite in the charge composition, as can be seen from Fig. 2, leads to a significant decrease in the electrical conductivity of materials under study, which is apparently associated with an 
increase in the titanium content in the solid solution. For example, a material with equiatomic carbon content of $0.25 \mathrm{wt} \%$ and titanium of $1 \mathrm{wt} \%$ has the highest electrical conductivity. This can be explained by the fact that in practice the weight of titanium in this case binds to carbon and forms the titanium carbide. An increase in the carbon content in the charge up to $0.45 \mathrm{wt} \%$ doesn't significantly influence on the electrical conductivity of materials under study with a titanium content of $1 \mathrm{wt} \%$. A further increase in the graphite content in the charge up to $1 \mathrm{wt} \%$ leads to a decrease in the electrical conductivity of materials under study, apparently, due to the formation of a significant amount of graphite inclusions. The maximum electrical conductivity in materials under study with a titanium content of 2 wt\% or more, shifts towards a higher content of graphite, which is quite explainable by the need for a larger amount of carbon to bind titanium atoms into carbides and exclude the possibility of a solid solution formation.

\subsection{Structure and phase composition}

The structure of composite materials of the Cu-Ti-C-O system studying, as can be seen from Fig. 3, depends on the amount of titanium introduced into the charge and the quantitative ratio of titanium and carbon additives. With an equiatomic ratio of alloying additions of titanium and carbon, the microstructure of the $\mathrm{Cu}-1.0 \mathrm{wt} \% \mathrm{Ti}-0,25 \mathrm{wt} \% \mathrm{C}$ material in a bright field consists of large granules of an inhomogeneous structure (Fig.3, a). There are light and dark areas inside these granules. The dark area (Fig. 3, c), in the image obtained in the differential interference contrast (DIC) mode contains a significant amount of pink inclusions of copper oxide. A measurement of the microhardness of granules of this material showed a significant spread of microhardness in different areas. As can be seen in the photo of a microstructure (Fig.3, $c$ ), taken in the DIC mode, there are separate areas with a large amount of pink microinclusions, which are copper oxide. With an increase in the titanium concentration in the charge under a constant amount of carbon introduced $(0.25 \mathrm{wt} \%)$, the formation of a more uniform structure in composite materials under study of the $\mathrm{Cu}-\mathrm{Ti}-\mathrm{C}-\mathrm{O}$ system as a result of reactionary mechanical alloying and hot extrusion is provided. The most uniform structure is observed in the composite $\mathrm{Cu}-3.0$ wt\%Ti-0.25 wt\%C under study (Fig.3, $b$ ). In these materials, the microinclusions of copper oxide are much less and they are mainly observed along the boundaries of granules (Fig.3, $d$ ).

All materials under study contain blue inclusions, the size of some of them reaches up to $50 \mu \mathrm{m}$, and they are located along the boundaries of granules. These inclusions are close in composition to the intermetallic compound $\mathrm{Cu}_{4} \mathrm{Ti}$. With an increase in the amount of titanium introduced, the amount of these inclusions becomes larger.

The results of measuring the copper matrix lattice period of composites under study are presented in Table 1. As the «metallic» radius of a titanium atom $\left(r_{\mathrm{Ti}}=0.143 \mathrm{~nm}\right)$ [19] is greater than the «metallic» radius of a copper atom $\left(r_{\mathrm{Cu}}=1.28\right)$, respectively, the formation of a solid solution of $\mathrm{Cu}(\mathrm{Ti})$ leads to an increase in the lattice parameter. Estimated values of titanium concentration in a solid solution, calculated according to Vegard's law, in composite materials under study depend on the amount of titanium and graphite introduced in the charge. An increase in the concentration of introduced titanium, at the same concentration of graphite in the charge, leads to an increase in the concentration of titanium in a solid solution, which correlates with a decrease in the electrical conductivity of materials under study (see Fig. 2). Finally, an increase in the graphite content to $0.45 \mathrm{wt} \%$ in the material $\mathrm{Cu}-3.0 \mathrm{wt} \% \mathrm{Ti}-0.45 \mathrm{wt} \% \mathrm{C}$ with a constant titanium content leads to a decrease in the titanium concentration in the solid solution due to the formation of dispersed particles of titanium carbide, which as a result significantly increases the electrical conductivity (see Fig. 2) and slightly increases the hardness (see Fig. 1). Thus, in the process of reactionary grinding of a powder mixture in the attritor and subsequent hot 
extrusion, the most part of titanium is used for the formation of dispersed particles of titanium carbide, and the formation of intermetallic compounds of copper and titanium as a result of a supersaturated solid solution decomposition, especially at a high titanium content, potentially can be.
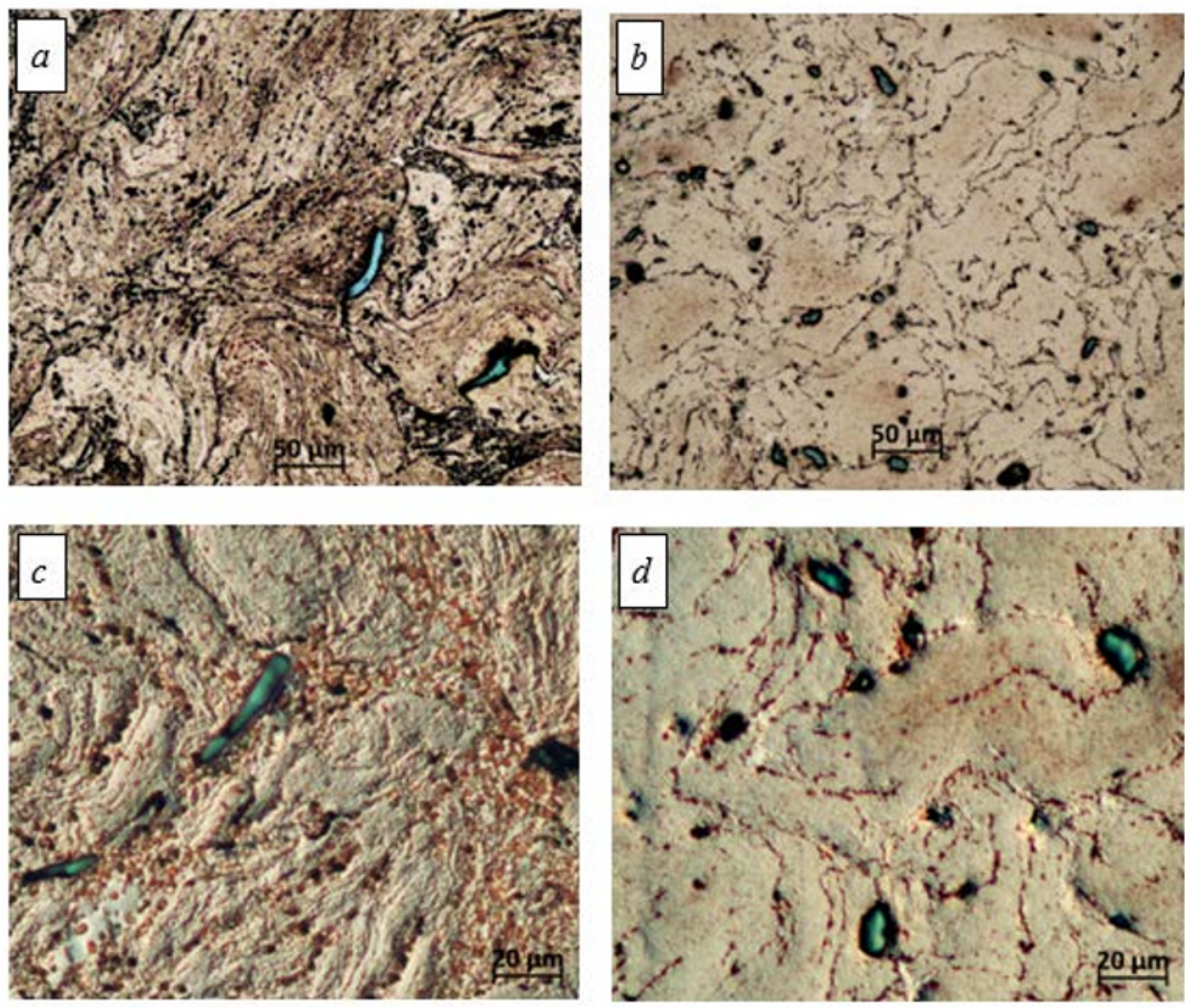

Fig. 3. The microstructure of composite materials $\mathrm{Cu}-1.0 \mathrm{wt} \% \mathrm{Ti}-0.25 \mathrm{C}(a, c)$ and $\mathrm{Cu}-3.0 \mathrm{wt} \% \mathrm{Ti}-0,25$ wt\%C $(b, d)$ under study in a bright field and in the DIC mode.

Table 1. The copper lattice parameter dependence on the titanium content in the charge of materials under study.

\begin{tabular}{|c|c|c|c|}
\hline \multirow{2}{*}{ Material } & \multirow{2}{*}{$\begin{array}{c}\text { Copper lattice } \\
\text { parameter, } \mathrm{nm}\end{array}$} & $\begin{array}{c}|c| \\
\text { in the } \\
\text { charge }\end{array}$ & $\begin{array}{c}\text { in the solid solution of } \\
\mathrm{Cu}(\mathrm{Ti})\end{array}$ \\
\cline { 3 - 4 } & & - & 0 \\
\hline $\mathrm{Cu}$ & 0.36151 & 1.0 & 0.17 \\
\hline $\mathrm{Cu}-1.0 \mathrm{wt} \% \mathrm{Ti}-0.25 \mathrm{wt} \% \mathrm{C}$ & 0.36160 & 2.0 & 0.29 \\
\hline $\mathrm{Cu}-2.0 \mathrm{wt} \% \mathrm{Ti}-0.25 \mathrm{wt} \% \mathrm{C}$ & 0.36166 & 3.0 & 0.43 \\
\hline $\mathrm{Cu}-3.0 \mathrm{wt} \% \mathrm{Ti}-0.25 \mathrm{wt} \% \mathrm{C}$ & 0.36172 & 3.0 & 0.25 \\
\hline $\mathrm{Cu}-3.0 \mathrm{wt} \% \mathrm{wi}-0.45 \mathrm{wt} \% \mathrm{C}$ & 0.36168 & \multicolumn{2}{|c}{} \\
\hline
\end{tabular}

In order to check the possibility of solid solution decomposition, the material Cu-3.0 wt\%Ti-0.25 wt\%C under study, with a significant titanium concentration in the solid solution and having an initial hardness of $240 \mathrm{HB}$ and an electrical conductivity of $50 \%$ IASC, was annealed at a temperature of $500{ }^{\circ} \mathrm{C}$. After annealing for $2 \mathrm{~h}$, the electrical conductivity increased to $56 \%$ IASC, which may be due to the additional decomposition of a solid solution. The hardness of the material under study after annealing at temperatures of 
$500{ }^{\circ} \mathrm{C}$ and $750{ }^{\circ} \mathrm{C}$ for $2 \mathrm{~h}$ does not change. A decrease in the hardness of this material begins at an annealing temperature above $950{ }^{\circ} \mathrm{C}$. For example, as opposed to materials under study, the softening of dispersion-hardened alloys $\mathrm{Cu}-4.0 \mathrm{wt} \% \mathrm{Ti}$ [6-9] begins with annealing above $550 \ldots 600^{\circ} \mathrm{C}$.

The results of X-ray phase analysis of anode deposits of materials under study show that the main dispersion-strengthening particles are the particles of titanium carbide TiC. All the main diffraction lines of titanium carbide are present in X-ray diffraction patterns of anode deposits isolated from composite materials under study. In X-ray diffraction patterns from anode deposits of the material Cu-1.0 wt\%Ti-0.25 wt\%C under study, in addition to lines from titanium carbide, the first three strong lines from titanium oxide $\mathrm{TiO}_{2}$ - rutile will be showed. With an increase in the titanium content above equiatomic one relative to graphite, the lines from titanium oxides disappear in X-ray diffraction patterns from anode deposits of materials under study, but traces of the presence of a stable $\beta$ - phase $\left(\mathrm{Cu}_{3} \mathrm{Ti}\right)$ appear in the form of a weak line with an interplanar distance of $0.199 \mathrm{~nm}$, which correlates with the data of X-ray phase analysis alloy $\mathrm{Cu}-4 \mathrm{wt} \% \mathrm{Ti}$ after aging [7]. According to the authors [6$10]$, this phase is formed along grain junction lines as a result of cellular or intermittent aging of a supersaturated solid solution of titanium in copper.

Atomic force microscopy studies using the Next NT-MTD scanning probe microscope showed that during the reactionary mechanical alloying of copper powder with titanium and carbon, highly fragmented matrix grains with sizes of $200 \mathrm{~nm}$ and less are formed in materials under study (Fig. 4). Separate fragments inside the grains, apparently, subgrains are much less than $100 \mathrm{~nm}$ in size. The picture of structure also shows precipitates in the form dark particles with sizes of $20 . .60 \mathrm{~nm}$. Most of these precipitations are located along the grain boundaries. It is most likely that such particles are titanium carbide, which were formed by the mechanisms described by the authors $[11,13]$. The parameters of the fine structure of materials under study given in this paper allow attributing them to bulk metalmatrix nanostructured composite materials [20-21].

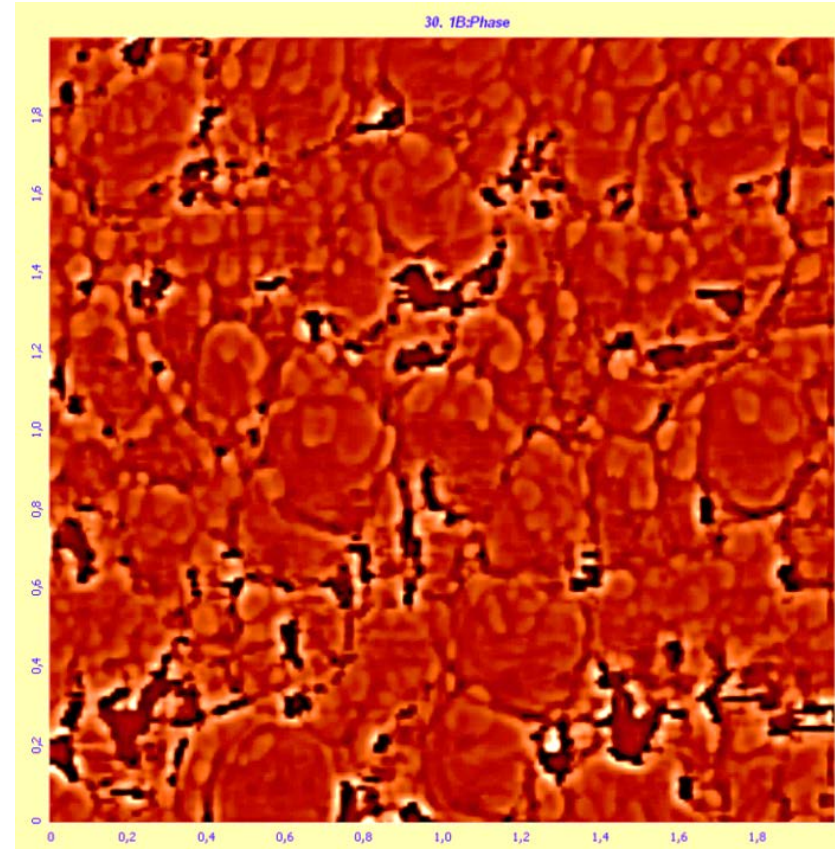

Fig.4. The structure of the composite material Cu-2.0 wt\%Ti-0.25wt\%C section surface (AFM, mode - phase). 


\section{Conclusions}

1. The data obtained confirm that composite materials of the $\mathrm{Cu}-\mathrm{Ti}-\mathrm{C}-\mathrm{O}$ system in terms of the values of hardness and electrical conductivity can be promising in solving tasks of replacing beryllium bronzes and are of interest for further increasing the field of application.

2. Integrated studies have shown that the materials under study, according to the geometric parameters of structural components, can be attributed to bulk metal-matrix nanostructured composite materials, in which titanium carbides $\mathrm{TiC}$ are the main dispersion strengthening particles.

3. The main advantage of dispersion-strengthened composite materials of the $\mathrm{Cu}-\mathrm{Ti}-\mathrm{C}-\mathrm{O}$ is a significantly high recrystallization temperature, in comparison with the precipitation hardening $\mathrm{Cu}-\mathrm{Ti}$ alloys.

\section{References}

1. A.K. Nikolaev, V.M., Rosenberg, Alloys for resistance welding electrodes (Metallurgy, Moscow, 1978)

2. A.V. Berdichevsky, E.N. Redkin, K.A. Ellik, Multi-electrode resistance welding machines (Energoatomizdat, Leningrad, 1984)

3. M. Feurer, Elektroerosive Metallbearbeitung: Materialabtrag durch Funkenerosion (Vogel - Buchverlag, Würzburg, 1983)

4. T. P. Taylor, M. Ding, D. S. Ehler, T. M. Foreman, J. P. Kaszuba, N. N. Sauer, Beryllium in the Environment: a Review, Journal of Environmental Science and Health, Part A, 38 (2), pp. 439-469 (2003)

5. A.N. Shah, M. Tanveer, S. Hussain, G. Yang, Beryllium in the environment: Whether fatal for plant growth? Reviews in Environmental Science and Bio/Technology, v.15, pp. 549-561 (2016)

6. A. Soffa, D.E. Laughlin, High-strength age hardening copper-titanium alloys: redivivus, Progress in Materials Science, 49(3-4), pp.347-366 (2004)

7. F. Hernandez-Santiago, N. Cayetano-Castro, V.M. Lopez-Hirata, H.J. DorantesRosales, J.J. Cruz-Rivera, Precipitation Kinetics in a Cu-4 mass \% Ti Alloy, Materials Transactions, 45(7), pp. 2312-2315 (2004)

8. Z. Rdzawski, J. Stobrawa, W. Głuchowski, J. Konieczny, Thermomechanical processing of CuTi4 alloy, Journal of Achievements in Materials and Manufacturing Engineering, 42(1-2), pp. 9-25 (2010)

9. J. Konieczny, Z. Rdzawski, Influence of cold working on microstructure and properties of annealing alloyed copper, Proc. of 14th International Materials Symposium (IMSP' 2012), pp. 633-641 (Pamukkale University, Denizli, Turkey, 2012)

10. V. M. Lopez-Hirataa , F. Hernandez-Santiagoa , M. L. Saucedo-Muñoza, H. J. Dorantes-Rosalesa, A. M. Paniagua-Mercado, Analysis of $\beta^{\prime}\left(\mathrm{Cu}_{4} \mathrm{Ti}\right)$ Precipitation During Isothermal Aging of a Cu-4wt.\%Ti Alloy, Materials Research, 21(5), e20180121 (2018)

11. T. Weissgaerber, Ch. Sauer, B. Kieback, Herstellung dispersionsverfestigter Kupferwerkstoffe durch mechanisches Legieren, Wissenschaftliche Zeitschrift der Technischen Unversitat Dresden, 46(1), pp. 4-39 (1997) 
12. F. Wang, Y. Li, K. Wakoh, Y. Koizumi, A. Chiba, Cu-Ti-C alloy with high strength and high electrical conductivity prepared by two-step ball-milling processes, Materials and Design, 61, pp.70-74 (2014)

13. F. Wang, Y Li, X. Wang, Y. Koizumi, Y. Kenta, A. Chiba, In-situ fabrication and characterization of ultrafine structured $\mathrm{Cu}-\mathrm{TiC}$ composites with high strength and high conductivity by mechanical milling, Journal of Alloys and Compounds, v. 657, pp. 122-132 (2016)

14. V.A. Dovydenkov, V.S. Simonov, E.P. Shalunov, M.V. Yarmolyk, Granule formation kinetics in the process of mechanical alloying and their influence upon the properties of materials $\mathrm{Cu}-\mathrm{Al}-\mathrm{O}-\mathrm{C}$ and $\mathrm{Cu}-\mathrm{Ti}-\mathrm{C}-\mathrm{O}$, Proc. of Int. Congress \& Exhibition on Powder Metallurgy (Euro PM - 2004), 1, pp. 177-180 (EPMA, Vienna, 2004)

15. E. Shalunov, A. Matrosov, L. Chen, Development, production and application of DISCOM $^{\circledR}$ copper nanocomposites as highly resource electrode and electric contact materials, Proc. of Int. Congress \& Exhibition on Powder Metallurgy (Euro PM 2008), 1, pp. 113-119 (EPMA, Mannheim, 2008)

16. E.P. Shalunov, V.M. Smirnov, Features of the formation of bulk nanostructured materials based on copper by the method of reaction mechanical alloying, Bulletin of the Chuvash University. Natural and technical sciences, 2, pp. 291-299 (2009)

17. E.P. Shalunov, V.M. Smirnov, A.L. Matrosov, Reactionary mechanical alloying of copper powder with oxygen and carbon, Bulletin of the Chuvash University, 3, pp. 252-259 (2012)

18. E.P. Shalunov, A.L. Matrosov, Ya.M. Lipatov, V.E. Staphik, Dispersion-strengthened material for butt welding electrodes, RU-Pat. 2118393 (1996)

19. B.F. Ormont, Introduction to physical chemistry and crystal chemistry of semiconductors (Higher school, Moscow, 1973)

20. Ch. Pool, F. Owens, Nanotechnologies: trans. from English (Technosphera, Moscow, 2004)

21. R.Z. Valiev, I.V. Aleksandrov, Nanostructured materials obtained by severe plastic deformation (Logos, Moscow, 2000) 